\title{
Estimativa de parâmetros de aquíferos através do coeficiente de recessão em áreas de embasamento cristalino de Minas Gerais
}

\author{
Aquifer parameter estimation through the recession coefficient in \\ basement areas of Minas Gerais
}

\section{Rebeca Ferreira Gonzaga} Silva

Mestre pelo Departamento de Geologia da Escola de Minas / UFOP E-mail: rebecagonzaga@yahoo.com.br

Luis de Almeida Prado Bacellar

Professor do Departamento de Geologia da Escola de Minas / UFOP E-mail: bacellar@degeo.ufop.br

\footnotetext{
Kênia Nassau Fernandes

Graduanda em Engenharia Ambiental da Escola de Minas / UFOP

E-mail: keniafernandes.ufop@folha.com.br
}

\section{Resumo}

O coeficiente de recessão $(\alpha)$ indica a taxa de produção do fluxo de base, que representa a porção da vazão de um rio mantida pela restituição de águas subterrâneas. Ele pode ser obtido através da análise de hidrogramas. Esse coeficiente possibilita o cálculo de parâmetros importantes, como a transmissividade de aquíferos, as reservas renováveis de água subterrânea e as vazões mínimas em canais de drenagem, que, usualmente, são obtidas através de outros índices hidrológicos, como o $\mathrm{Q}_{7,10}$, muito empregado na gestão de recursos hídricos superficiais. As bacias estudadas estão localizadas na porção centro-sul de Minas Gerais, em regiões de rochas granito-gnássicas, sob vegetação, clima e uso e ocupação semelhantes. Os resultados obtidos, no estudo, foram satisfatórios, indicando os métodos de determinação de coeficiente de recessão como promissores para se caracterizar a produção de água subterrânea em bacias hidrográficas do embasamento cristalino. A restituição de águas subterrâneas para os sistemas de drenagem é maior nas áreas de relevo mais suave, indicando que estas constituem as melhores áreas de recarga.

Palavras-chave: Água subterrânea, recessão, fluxo de base.

\section{Abstract}

The recession coefficient $(\alpha)$ indicates the production rate of the baseflow, that represents the part of the river flow which is predominately maintained by groundwater restitution. It can be obtained through hydrographic analysis. This coefficient allows the calculation of important parameters, such as aquifer transmissivity, renewable groundwater reserves, and low flow in drainage channels that usually are obtained through other hydrological indexes, such as the $Q_{7,10}$, frequently used in the management of surficial hydrological resources. The studied basins are located in the Central-Southern region of the Minas Gerais State, in areas of granite-gneissic rocks, with similar vegetation, climate and landuse. The results were satisfactory, showing that the determination methods for the recession coefficients may be used to characterize groundwater production in the hydrographic basins of the crystalline basement. The groundwater discharged into the drainage systems is greater in areas with smoother relief, indicating that they constitute the best recharge areas.

Keywords: Groundwater, recession, baseflow. 
Estimativa de parâmetros de aquíferos através do coeficiente de recessão em áreas de embasamento..

\section{Introdução}

A forte conexão entre o regime de recarga e descarga da água subterrânea e os demais componentes do fluxo hidrológico influencia diretamente na vazão dos cursos d’água. Sendo assim, a análise das vazões em uma bacia, ao longo do tempo, permite a obtenção de dados importantes para a caracterização dos aquíferos, do regime de fluxo e do armazenamento subterrâneo, através de seus parâmetros hidrológicos (Dewandel et al., 2002; Costa, 2005; Mourão, 2007).

A análise de hidrogramas possibilita a interpretação de várias singularidades da bacia. Entre os índices que podem ser definidos, a partir de hidrogramas, o coeficiente de recessão ou de esgotamento $(\alpha)$ foi o mais utilizado nesse trabalho. Esse coeficiente indica a taxa de produção do fluxo de base, que é constituído pelo percentual de vazão de um rio mantido pela restituição de águas subterrâneas (Custodio \& Llamas, 1976). O coeficiente de recessão permite obter informações sobre as vazões mínimas em canais de drenagem e determinar as reservas renováveis do aquífero, que correspondem ao volume de água total renovado anualmente no mesmo. As vazões mínimas são, usualmente, obtidas através de outros índices hidrológicos, como o $Q_{7,10}$, muito empregado na gestão de recursos hídricos superficiais.

O coeficiente de recessão possibilita, ainda, o cálculo de outros parâmetros importantes, como a transmissividade média de aquíferos. A transmissividade (T) é a taxa de escoamento de água através de uma faixa vertical do aquífero, com largura unitária, submetida a um gradiente hidráulico unitário (Feitosa, 1997). Esse parâmetro é, tradicionalmente, obtido por métodos diretos, sobretudo por testes de bombeamento de aqüíferos (Custodio \& Llamas, 1976), que são raramente feitos, pela dificuldade operacional e alto custo de execução.

As seis bacias estudadas ocorrem em regiões de complexos metamórficos, com predomínio de rochas gnáissicas, migmatíticas e graníticas, sob vegetação, clima e uso e ocupação semelhantes e localizadas na porção centro-sul de Minas Gerais (Figura 1). A bacia Fazenda Maracujá está inserida no Complexo Metamórfico Bação, dentro do Quadrilátero Ferrífero (QF). As outras bacias estão localizadas a oeste do QF, no Complexo Metamórfico Campo Belo.

Na região, predominam formas de relevo de colinas e morrotes, em planaltos dissecados. As amplitudes de relevo são, geralmente, baixas e os fundos de vales encontram-se normalmente assoreados. O padrão de drenagem é dendrítico, assumindo arranjo mais angular nas zonas mais fraturadas.

O clima da região é tropical, com temperaturas médias variando entre $16^{\circ} \mathrm{C}$ e $24^{\circ} \mathrm{C}$. A precipitação média anual varia entre 1200 a $1500 \mathrm{~mm}$, com o período mais chuvoso do ano de outubro a março (CETEC, 1983).

Costa (2005) trabalhou com microbacias $\left(\leq 1 \mathrm{~km}^{2}\right)$ em áreas do embasamento e encontrou uma relação inversa entre o coeficiente de recessão e a produção de fluxo de base. Sendo assim, bacias com menor coeficiente de recessão são, potencialmente, mais eficientes em termos de armazenamento de água subterrânea e de produção de fluxo de base.

O objetivo principal desse trabalho foi o de determinar a produção de água subterrânea (fluxo de base) em bacias hidrográficas do embasamento cristalino através de métodos indiretos, utilizando séries históricas de vazão. Secundariamente, pretende-se avaliar a influência da escala da bacia e do relevo na produção de fluxo de base e das reservas renováveis de água subterrânea das bacias.

\section{Materiais e métodos}

A partir da sobreposição dos mapas geológico, topográfico e hidrológico em ambiente Gis (ArcGis 9.0), foram selecionadas seis bacias em área de embasamento cristalino de geologia predominante granito-gnáissica e migmatítica, na região centro-sul de Minas
Gerais. A bacia Fazenda Maracujá foi escolhida desde o início do projeto, por já ser muito estudada (Bacellar, 2000, Costa, 2005), servindo de base para escolha das demais. Foram selecionadas três bacias menores (entre elas, a bacia Fazenda Maracujá) e três maiores, com o intuito de avaliar a interferência da escala no comportamento hidrológico das mesmas.

Os critérios para essa seleção foram: áreas com geologia, geomorfologia e condições climáticas e de uso e ocupação o mais semelhantes possível com as da bacia Fazenda Maracujá; bacias hidrográficas que apresentassem série histórica de dados hidrológicos consistentes e de tamanho satisfatório (com mais de sete anos de monitoramento), no banco de dados da Agência Nacional de Águas (ANA).

Com exceção da bacia Fazenda Maracujá, que já havia sido delimitada e caracterizada em trabalhos anteriores (Bacellar, 2000, Costa, 2005) e cuja série histórica de vazões foi disponibilizada pela CEMIG, as outras foram obtidas no site HidroWeb, da ANA. Todas as bacias selecionadas possuem dados históricos de vazão de muitos anos (Tabela 1).

Utilizando-se das séries hidrológicas históricas, foram construídos hidrogramas diários e anuais (de vazões médias mensais). A caracterização dos períodos de recessão foi feita em hidrogramas anuais em escala semilogarítmica, pelo método de Barnes (Custodio \& Llamas, 1976).

Calcularam-se dois índices morfométricos para as bacias, slope index (Lacey \& Grayson, 1998) e índice de compacidade (Custodio \& Llamas, 1976), a partir de informações (em escala 1:50000) de cartas topográficas (área, perímetro, altitude mínima e máxima e distância média do canal de drenagem ao inteflúvio (L)) com emprego do programa ARCGIS.

Foram determinados os coeficientes de recessão $(\alpha)$ para cada bacia através dos métodos de Maillet ou Barnes (Dewandel et al, 2002), Boussinesq 
(Dewandel et al., 2002), Matching Strip (Snyder, 1935, Mello et al., 1994, Tallaksen, 1995), Correlação (Langbein, 1938; Nathan \& McMahon, 1990; Tallaksen, 1995; Smakhtin, 2001) e Drogue (Kresic, 1997). O cálculo com o Método da Correlação empregou dois diferentes intervalos de tempo, 3 e 5 dias (Langbein, 1938; Costa, 2005). Os métodos de Maillet, de Boussinesq e de Drogue permitem calcular a recessão em hidrogramas com médias mensais de longo prazo de vazões, ao passo que os métodos Matching Strip e de Correlação possibilitam o cálculo da recessão em hidrogramas diários, com base na determinação de uma curva de reces- são mestra (Silva, 2009). Os métodos de Maillet, de Correlação e Matching Strip adotam uma relação exponencial para a restituição de água subterrânea, enquanto que os outros assumem outras relações, como a quadrática (Kresic, 1997; Dewandel et al., 2002).

Foram utilizados três valores de coeficiente de armazenamento (mínimo, médio e máximo) para o cálculo da transmissividade, todos baseados em valores encontrados na literatura (Silva, 1994; Costa, 2005), mas, nesse trabalho, somente são apresentados os resultados com os valores médios. A transmissividade ( $\mathrm{T}$ ) foi determinada, indiretamente, através das equações de Maillet,
Boussinesq e Brutsaert (Szilagyi et al., 1997; Brutsaert \& Lopez, 1998; Mendoza, 2003; Malvicini, 2005), tomando-se, por base, os valores de $\alpha$ e do coeficiente de armazenamento (S), além de outras informações das bacias, tais como área (A), distância média da drenagem ao divisor topográfico (L), entre outros (Silva, 2009). Essas equações reproduzem modelos conceituais de restituição de água subterrânea para canais de drenagem (Dewandel et al., 2002).

Para complementar os resultados e possibilitar um maior número de correlações, realizaram-se cálculos das reservas renováveis e de $\mathrm{Q}_{7,10}$ para cada bacia. $\mathrm{O}$ $\mathrm{Q}_{7,10}$ (vazão mínima de sete dias com

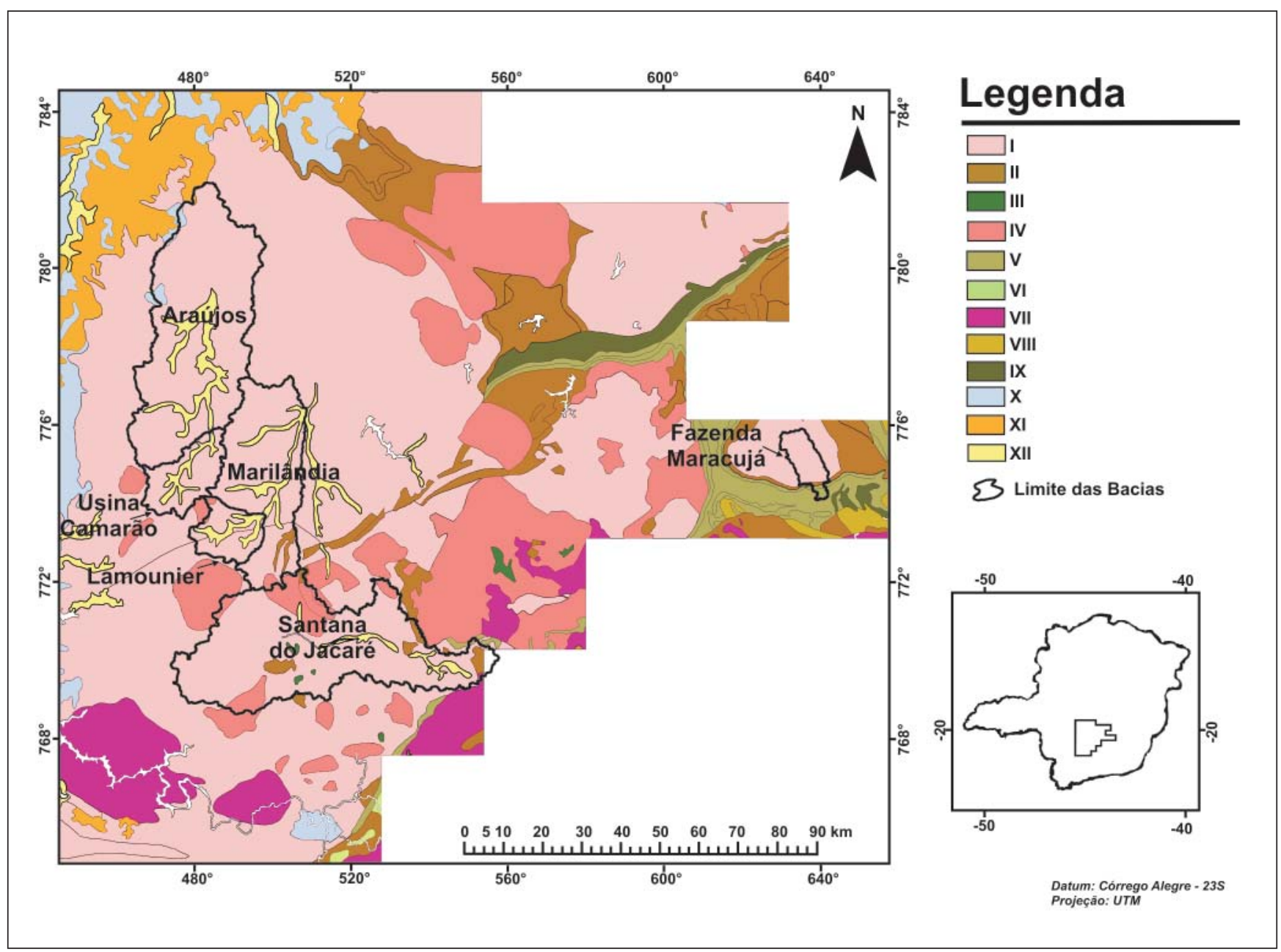

Figura 1 - Mapa geológico da região destacando a localização das bacias. Descrição da legenda: I - Complexos Metamórficos (gnaisses, migmatitos e granitóides); II - Supergrupo Rio das Velhas (xistos, quartzitos metaultramáficos); III - Rochas metamáficas; IV - Granitóides; V - Supergrupo Minas (xistos, filitos, quartzitos, itabiritos e dolomitos); VI - Metagabros e metadioritos; VII - Suíte Alto Maranhão (tonalito e granito calcialcalino metaluminoso); VIII - Grupo Itacolomi (quartizitos, filitos, metaconglomerados); IX - Grupo Sabará (clorita xisto, metatufo, metagrauvaca); X - Supergrupo São Francisco (pelitos, carbonatos e dolomitos); XI - Coberturas detrítico-lateríticas; XII - Depósitos aluviais quaternários. 
Estimativa de parâmetros de aquíferos através do coeficiente de recessão em áreas de embasamento...

tempo de recorrência de dez anos) é um dos índices mais empregados para determinação de fluxos mínimos médios em canais de drenagem e, por consequência, útil para a gestão de recursos hídricos superficiais. Ele foi fornecido pelo IGAM, calculado através do Sistema Integrado de Meio Ambiente (SIAM). As reservas renováveis foram calculadas com o método de Barnes (Custodio \& Llamas, 1976), a partir da determinação em hidrogramas dos valores de fluxo de base máximo $\left(\mathrm{Q}_{0}\right)$.

Finalmente, fez-se o cruzamento de todos os parâmetros e índices calculados e a comparação de seus resultados.

\section{Resultados e discussão}

Na Tabela 1, encontram-se o intervalo de monitoramento e os índices morfométricos determinados para as bacias. Silva (2009) demonstrou que há uma relação inversa entre a declividade média (slope index) e a área das bacias monitoradas, ou seja, bacias situadas em zonas de cabeceiras, de menor ordem hierárquica,como as bacias Fazenda Maracujá e Usina Camarão, apresentam maiores valores de slope index. Bacias de maior ordem hierárquica, como a Santana do Jacaré, apresentam relação inversa.
Os diversos métodos de determinação do coeficiente de recessão apresentaram certa variabilidade em seus resultados finais (Tabela 2 ), o que era previsto, já que partem de pressupostos e conceituações teóricas diversos (Silva, 2009).

Os métodos de Maillet e Boussinesq apresentaram coeficientes de recessão mais próximos aos valores médios encontrados na literatura para outras áreas de embasamento cristalino de Minas Gerais (Peixoto et al., 1982; Gonçalves, 2001; Costa, 2005). Como discutido por Silva (2009), diferentemente desses métodos, os métodos Matching Strip, da Correlação e Drogue não apresentaram

Tabela 1 - Principais índices das bacias.

\begin{tabular}{l|c|c|c|c|c}
\hline \multicolumn{1}{c|}{ Bacias } & $\left.\mathbf{A ~} \mathbf{( k m}^{2}\right)$ & $\mathbf{L}(\mathbf{m})$ & Slope index & $\begin{array}{c}\text { Índice de } \\
\text { compacidade (Kc) }\end{array}$ & $\begin{array}{c}\text { Período de } \\
\text { monitoramento (anos) }\end{array}$ \\
\hline 1.Araújos & 1217 & 10750 & 12,67 & 1,6 & 40 \\
\hline 2.Lamounier & 157 & 5911 & 36,951 & 1,5 & 25 \\
\hline 3.Fazenda Maracujá & 116 & 4356 & 33,425 & 1,5 & 7 \\
\hline 4.Marilândia & 1027 & 10721 & 13,948 & 1,6 & 40 \\
\hline 5.Santana do Jacaré & 1547 & 9800 & 11,95 & 2,1 & 68 \\
\hline 6.Usina Camarão & 251 & 5498 & 23,48 & 1,6 & 40 \\
\hline
\end{tabular}

Tabela 2 - Coeficientes de recessão, transmissividades médias, $Q_{7,10}$ e reservas renováveis determinados para as bacias.

\begin{tabular}{|c|c|c|c|c|c|c|c|c|c|c|c|}
\hline \multirow{3}{*}{ Bacias } & \multicolumn{6}{|c|}{ Coeficientes de recessão $(\alpha)$ para cada método $\left(\mathrm{d}^{-1}\right)$} & \multicolumn{3}{|c|}{$\mathrm{T}\left(\mathrm{m}^{2} /\right.$ dia) para $\mathrm{S}=0,1$} & \multirow{3}{*}{$\begin{array}{l}Q_{7,10} \\
\left(\mathrm{~m}^{3} / \mathrm{s}\right)\end{array}$} & \multirow{3}{*}{$\begin{array}{l}\text { Reservas } \\
\text { renováveis } \\
\qquad\left(10^{6} \mathrm{~m}^{3}\right)\end{array}$} \\
\hline & \multirow{2}{*}{ (M) } & \multirow{2}{*}{ (B) } & \multirow{2}{*}{ (D) } & \multirow{2}{*}{ (MS) } & \multicolumn{2}{|c|}{ (C) } & \multirow{2}{*}{ (M) } & \multirow{2}{*}{ (B) } & \multirow{2}{*}{ (BR) } & & \\
\hline & & & & & $t=3$ & $\mathrm{t}=\mathbf{5}$ & & & & & \\
\hline 1. Araújos & 0,00566 & 0,00542 & 0,00536 & 0,00092 & 0,00111 & 0,00100 & 25,14 & 53,32 & 1805,77 & 4,6 & 249,98 \\
\hline 2. Lamounier & 0,00501 & 0,00504 & 0,00546 & 0,00108 & 0,00208 & 0,00125 & 23,80 & 53,04 & 7386,20 & 1,27 & 45,39 \\
\hline 3. Fazenda Maracujá & 0,00656 & 0,00621 & 0,01034 & 0,00128 & 0,00332 & 0,00199 & 29,95 & 62,78 & 5111,44 & 0,56 & 18,44 \\
\hline 4. Marilândia & 0,00600 & 0,00507 & 0,00786 & 0,00120 & 0,00221 & 0,00199 & 25,43 & 47,54 & 792,44 & 6,29 & 195,84 \\
\hline 5. Santana do Jacaré & 0,00472 & 0,00435 & 0,00468 & 0,00169 & 0,00208 & 0,00125 & 18,65 & 38,01 & 1260,12 & 5,85 & 460,47 \\
\hline 6. Usina Camarão & 0,00525 & 0,00579 & 0,00968 & 0,00089 & 0,00277 & 0,00166 & 28,99 & 70,84 & 9483,86 & 1,24 & 67,04 \\
\hline
\end{tabular}

Métodos utilizados: (M) Maillet; (B) Boussinesq; (D) Drogue; (MS) Matching Strip; (C) Correlação; (BR) Brutsaert. 
boas correlações entre si e nem com os índices morfométricos e demais parâmetros hidrodinâmicos estudados. Por outro lado, os coeficientes de recessão determinados pelos métodos de Maillet e Boussinesq apresentaram relação inversa com as áreas das respectivas bacias e direta com o slope index (Tabelas $1 \mathrm{e}$ 2). O método de Boussinesq é, teoricamente, mais exato que o de Maillet, uma vez que obedece fielmente às equações de fluxo hídrico subterrâneo (Dewandel et al., 2002), e não se comporta de forma linear como assumido na simplificação adotada por Maillet.

Os valores de transmissividade calculados pelos métodos de Maillet e Boussinesq também apresentaram resultados bem coerentes entre si (Figura 2a) e com os valores obtidos na literatura (Figura 2b) para outras áreas de embasamento.

Cabe destacar que o coeficiente de recessão é proporcional à transmissividade e inversamente proporcional à capacidade de armazenamento dos aquíferos da bacia (Dewandel et al, 2002), ou seja, quanto menor o $\alpha$, maior a capacidade de manter a vazão dos rios por períodos maiores pela contribuição do aquífero.

Em função de o Método de Boussinesq ser teoricamente mais exato, as próximas análises só envolverão os parâmetros determinados pelo referido método. A transmissividade com esse método apresentou relação inversa com a área das bacias e com o índice $\mathrm{Q}_{7,10}$ (Figura 3). Silva (2009) atribuiu esse comportamento a possíveis diferenças nos aquíferos envolvidos. Nas bacias de cabeceiras, como a bacia Maracujá (3) e Usina Camarão (6), o relevo é mais íngreme e o regolito, em média, mais delgado. Em tais bacias, os fluxos envolveriam, preferencialmente, os aquíferos fissurais, tradicionalmente considerados como de maior condutividade hidráulica e menor coeficiente de armazenamento. As bacias topograficamente mais suaves, como a Santana do Jacaré (5), tendem a ter fluxo mais concentrado no regolito, com porosidade intergranular e com características hidrodinâmicas opostas. Portanto as bacias mais íngremes apresentariam maiores valores de transmissividade e fluxos de base menos sustentáveis (menores $\mathrm{Q}_{7,10}$ ).

Na Figura 4, nota-se que as bacias maiores e de relevo mais suave (1, 4 e 5) possuem as maiores reservas renováveis, enquanto as menores e mais íngremes (2, 3 e 6) apresentam os menores valores. Silva (2009) demonstrou que essas relações se mantêm, mesmo quando os dados de $\mathrm{Q}_{7,10}$ e de slope index são cruzados com os das reservas renováveis específicas (reservas renováveis/área da bacia).

Portanto o fluxo de base é muito influenciado pela geomorfologia, pois, quanto mais suave é a declividade média da bacia - expressa pelo slope index -, maior a produção de água subterrânea, expressa por coeficientes de recessão baixos ou por reservas renováveis de água e $\mathrm{Q}_{7,10}$ elevados. Comprova-se, assim, que as bacias com relevo mais suave constituem as melhores áreas de recarga na região. Por outro lado, as bacias de cabeceiras, com menores áreas e relevo mais íngreme, contribuem menos para a recarga e para as reservas renováveis.

Como é possível determinar o coeficiente de recessão com menor volume de dados que o $\mathrm{Q}_{7,10}$ (Costa, 2005), abrese, dessa forma, uma possibilidade de se determinarem fluxos mínimos e outros parâmetros hidrológicos e hidrogeológicos com esses métodos alternativos, auxiliando na gestão da água subterrânea.

\section{Conclusões}

Os métodos alternativos de determinação de parâmetros de aquíferos através de análise de hidrogramas se mostraram promissores para caracterizar a produção de água subterrânea em bacias hidrográficas do embasamento cristalino, por serem de baixo custo e de fácil execução. O coeficiente de recessão pode, também, ser útil para a gestão de recursos hídricos superficiais e subterrâneos, uma vez que permite a

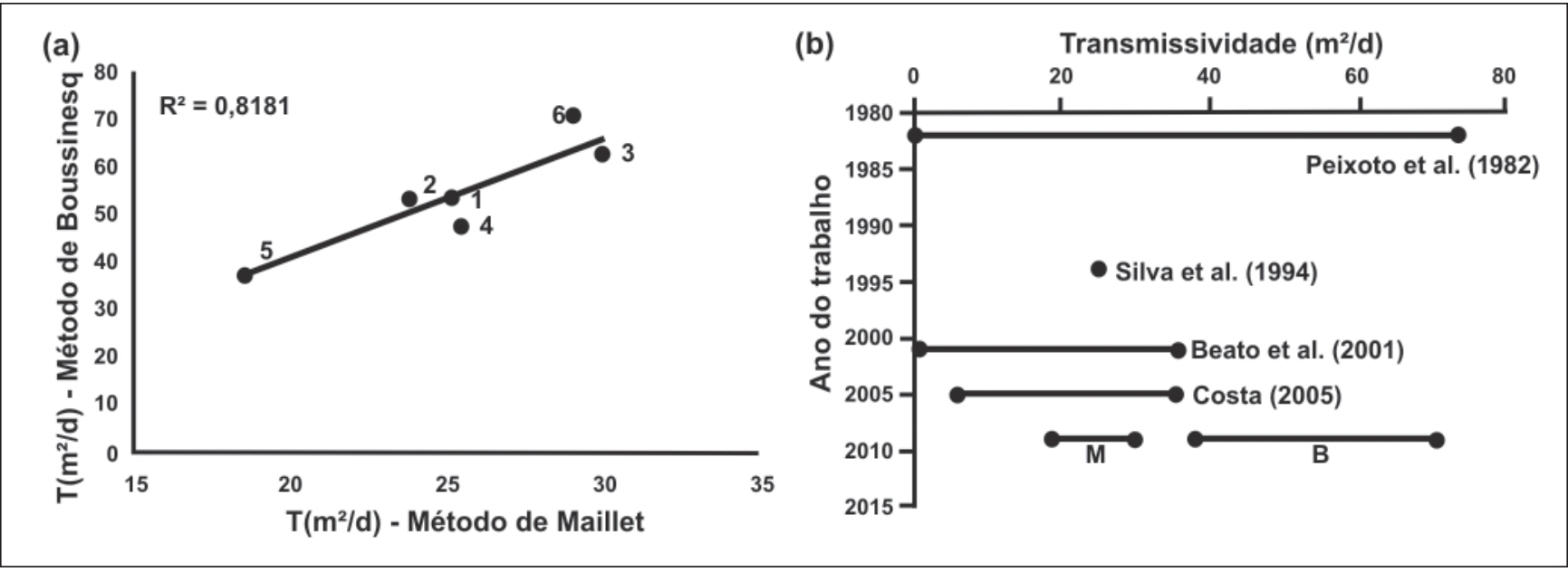

Figura 2 - (a) Gráfico destacando a relação direta entre as transmissividades pelos métodos de Maillet e Boussinesq. (b) Comparativo entre os valores de transmissividade obtidos por diversos autores e nas bacias monitoradas com os métodos de Maillet (M) e Boussinesq (B). 
Estimativa de parâmetros de aquíferos através do coeficiente de recessão em áreas de embasamento...

determinação da transmissividade média dos aquíferos e das reservas renováveis de água subterrâneas.

Entre os métodos analisados, o de Boussinesq apresentou valores de coeficientes de recessão e transmissividades mais próximos dos disponíveis na literatura, além de ter produzido as melhores correlações com parâmetros hidrológicos $\left(\mathrm{Q}_{7,10}\right)$ e com índices morfométricos.

Em áreas do embasamento cristalino do centro sul de Minas Gerais, a restituição de águas subterrâneas para os sistemas de drenagem é maior nas bacias com maiores áreas e com relevo mais suave, indicando que estas constituem as melhores áreas de recarga.
Contudo, para confirmar a adequabilidade do coeficiente de recessão como índice hidrológico e hidrogeológico de relevância, recomenda-se que esses estudos sejam ampliados de forma a envolver mais bacias hidrográficas desta e de outras áreas fisiográficas.

\section{Agradecimentos}

À CEMIG, pelos dados de vazão da bacia Fazenda Maracujá; ao IGAM, por fornecer os valores de $\mathrm{Q}_{7,10}$; e à FAPEMIG, pelos recursos disponibilizados pelo projeto EDT 3000/06.

\section{Referências bibliográficas}

BACELLAR, L. A. P. Condicionantes geológicos, geomorfológicos e geotécnicos dos mecanismos de voçorocamento na bacia do Rio Maracujá, Ouro Preto, MG. COPPE, Universidade Federal do Rio de Janeiro, 2000. 226p. (Tese de Doutorado).

BRUTSAERT, W., LOPEZ, J. P. Basin-scale geohydrologic drought flow reatures of riparian aquifers in the southern great plains. Water Resour. Res. 34, v. 2, 1998. 233-240p.

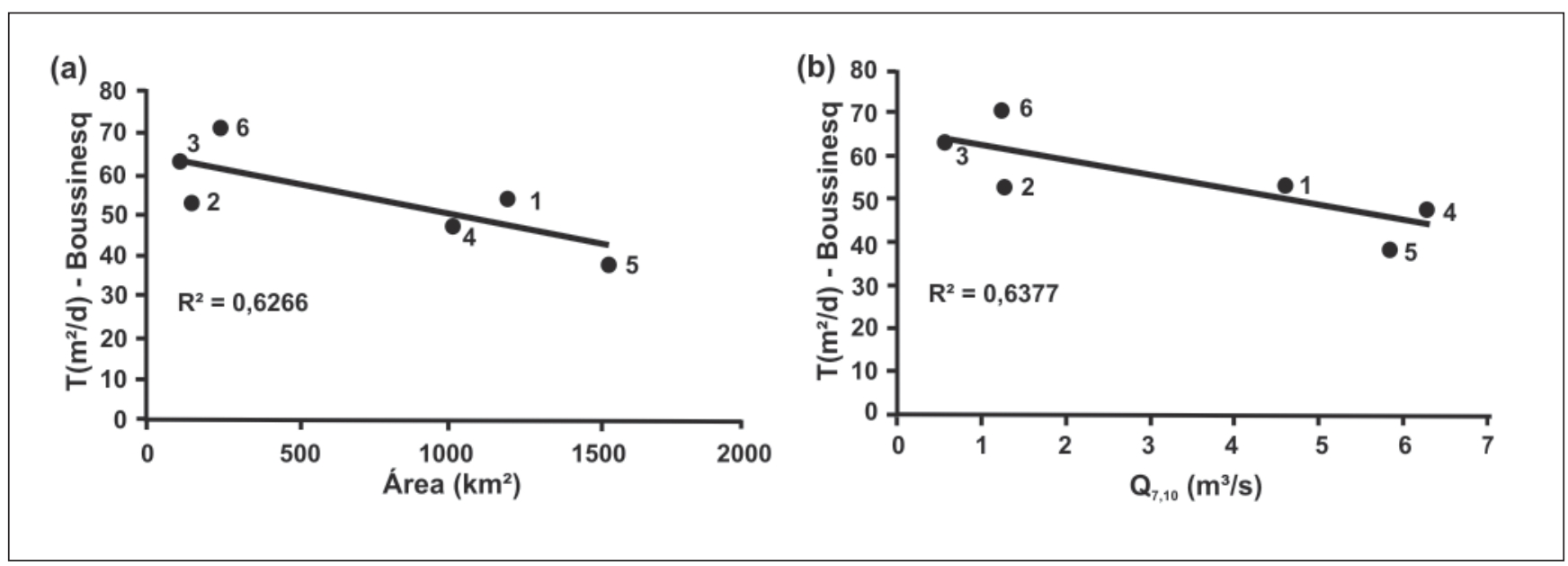

Figura 3 - (a) Comparativo entre a transmissividade calculada pelo método de Boussinesq e a área da bacia. (b) Comparativo entre a transmissividade de Boussinesq e a $Q_{7,10}$.

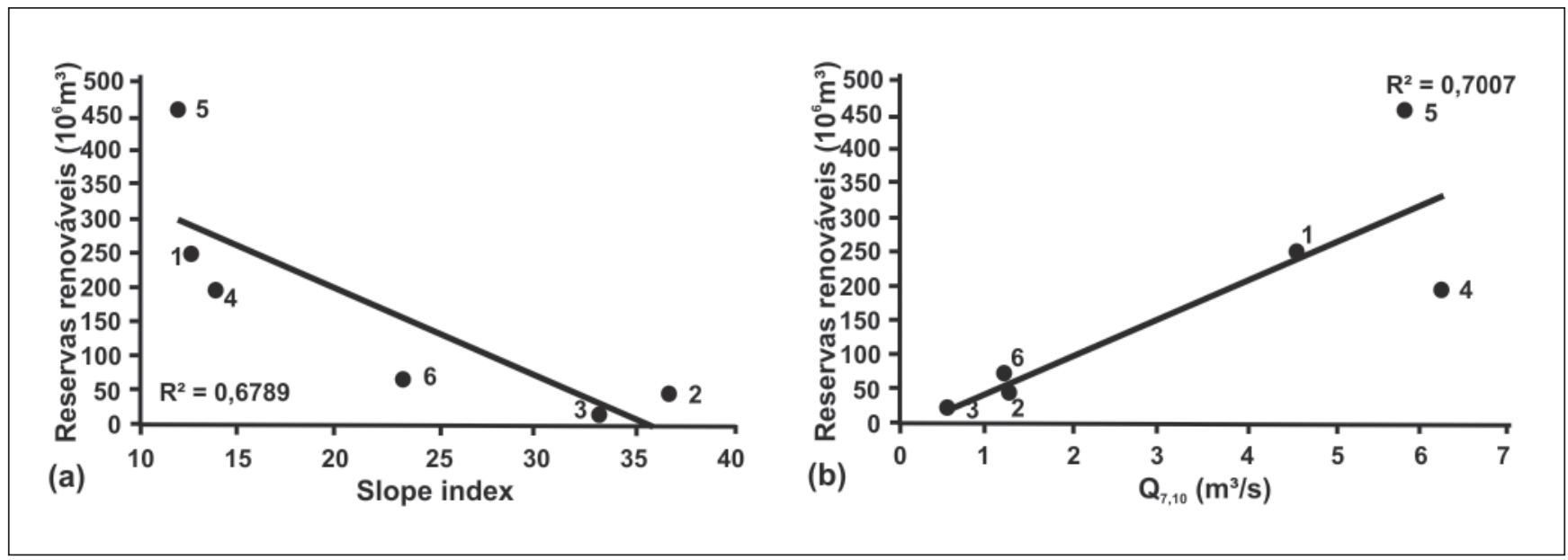

Figura 4 - Relação entre as reservas renováveis de água das bacias e os índices slope index (a) e $\mathrm{Q}_{7,10}$ (b). 
Rebeca Ferreira Gonzaga Silva et al.

CETEC. Diagnóstico Ambiental do Estado de Minas Gerais. Fundação Centro Tecnológico de Minas Gerais / CETEC. Belo Horizonte: 1983. 158p. (Séries de Publicações Técnicas / SPT010).

COSTA, F. M. Análise por métodos hidrológicos e hidroquímicos de fatores condicionantes do potencial hídrico de bacias hidrográficas - estudo de casos no Quadrilátero Ferrífero (MG). Ouro Preto: UFOP, 2005. 147p. (Dissertação de Mestrado).

CUSTODIO, E., LIAMAS, M. R. Hidrologia subterrânea. Barcelona: Ediciones Omega S.A., 1976. v. 2. 1157p.

DEWANDEL, B., LACHASSAGNE, P., BAKALOWICZ, M., WENG, P. H., AL-MALKI, A. Evaluation of aquifer thickness by analysing recession hydrographs. Aplication to the Oman ophiolite had-rock aquifer. Journal of Hydrology, 274, p. 248-269, 2002.

FEITOSA, A. C., MANOEL FILHO, J. Hidrogeologia: conceitos e aplicações. Fortaleza: CPRM, LABHID-UFPE, 1997. 412p.

GONÇALVES, J. A. C. Contribuição à hidrogeologia e à hidroquímica do leste da Zona da Mata de Minas Gerais e do estremo noroeste do Estado do Rio de Janeiro. Ouro Preto, UFOP: 2001. 101p. (Dissertação de Mestrado).

KRESIC, N. Quantitative solutions in hydrogeology and groundwater modeling. Florida: CRC Press LLC, 1997. 461p.
LACEY, G. C., GRAYSON, R. B. Relating baseflow to catchment properties in south-eastern Australia. Journal of Hydrology, 204, p. 231-250, 1998.

LANGBEIN, W. B. Some channel-storage studies and their application to the determination of infiltration. Reports and Papers, Hydrology, AGU, 19, p. 435-447, 1938.

MALVICINI, C. F., STEENHUIS, T. S., WALTER, M. T., PARLANGE, J. Y., WALTER, M. F. Evaluation of spring flow in the uplands of Matalom, Leyte, Philippines. Advances in Water Resources, 28, p. 1083-1090, 2005.

MELLO, M. H. DE A., PEDRO, JR M. J., LOMBARDI, NETO F. Hidrologia, climatologia e grometeorologia. In: BERTOLINI, D. et al. Potencialidades agrícolas das terras do Estado de São Paulo. Manual Técnico de Manejo e Conservação de Solo e Água, 2, 1994. p. 1-68.

MENDOZA, G. F. et al. Estimating basin-wide hydraulic parameters of a semi-arid mountainous watershed by recession-flow analysis. Journal of Hydrology, 279, p. 5769, 2003.

MOURÃO, M. A. A. Caracterização hidrogeológica do aquífero Cauê, Quadrilátero Ferrífero, MG. Belo Horizonte: UFMG, 2007. 297p. (Tese de Doutorado).

NATHAN, R. J., MCMAHON, T. A. Evaluation of automated techniques for base flow and recession analyses. Water Resources Research, 26, p. 1465-1473, 1990.

PEIXOTO, C. A. M., JARDIM, F. G., COSTA, P. C. G. Potencial hidrogeológico da região nordeste de Minas Gerais. In: CONGRESSO BRASILEIRO DE ÁGUAS SUBTERRÂNEAS, 2. Anais... Salvador: ABAS, 1982. p. 89-105.

SILVA, A. B., NETO, A. F. S., BERTACHINI, A. C. Potencial das águas subterrâneas do Quadrilátero Ferrífero. In: CONGRESSO BRASILEIRO DE ÁGUAS SUBTERRÂNEAS, 8. Anais... Recife: ABAS, 1994. p. 264-273.

SILVA, R. F. G. Estimativa de parâmetros hidrodinâmicos de aquíferos em áreas de embasamento através de métodos indiretos. Ouro Preto: UFOP, 2009. 109p. (Dissertação de mestrado).

SMAKHTIN, V. U. Low flow hydrology: a review. Journal of Hydrology, 240, p. 147-186, 2001.

SNYDER, F. F. A conception of runoff-phenomena. Reports and papers. Hydrology: AGU, 20, 1939. p. 725-738.

SZILAGYI, J., PARLANGE, M. B. Baseflow separation based on analytical solutions of the Boussinesq equation. Journal of Hydrology, 204, p. 251-260, 1997.

TALLAKSEN, L. M. A review of baseflow recession analysis. Journal of Hydrology, 165, p. 349-370, 1995.

Artigo recebido em 27/11/2009 e aprovado em 25/03/2010.

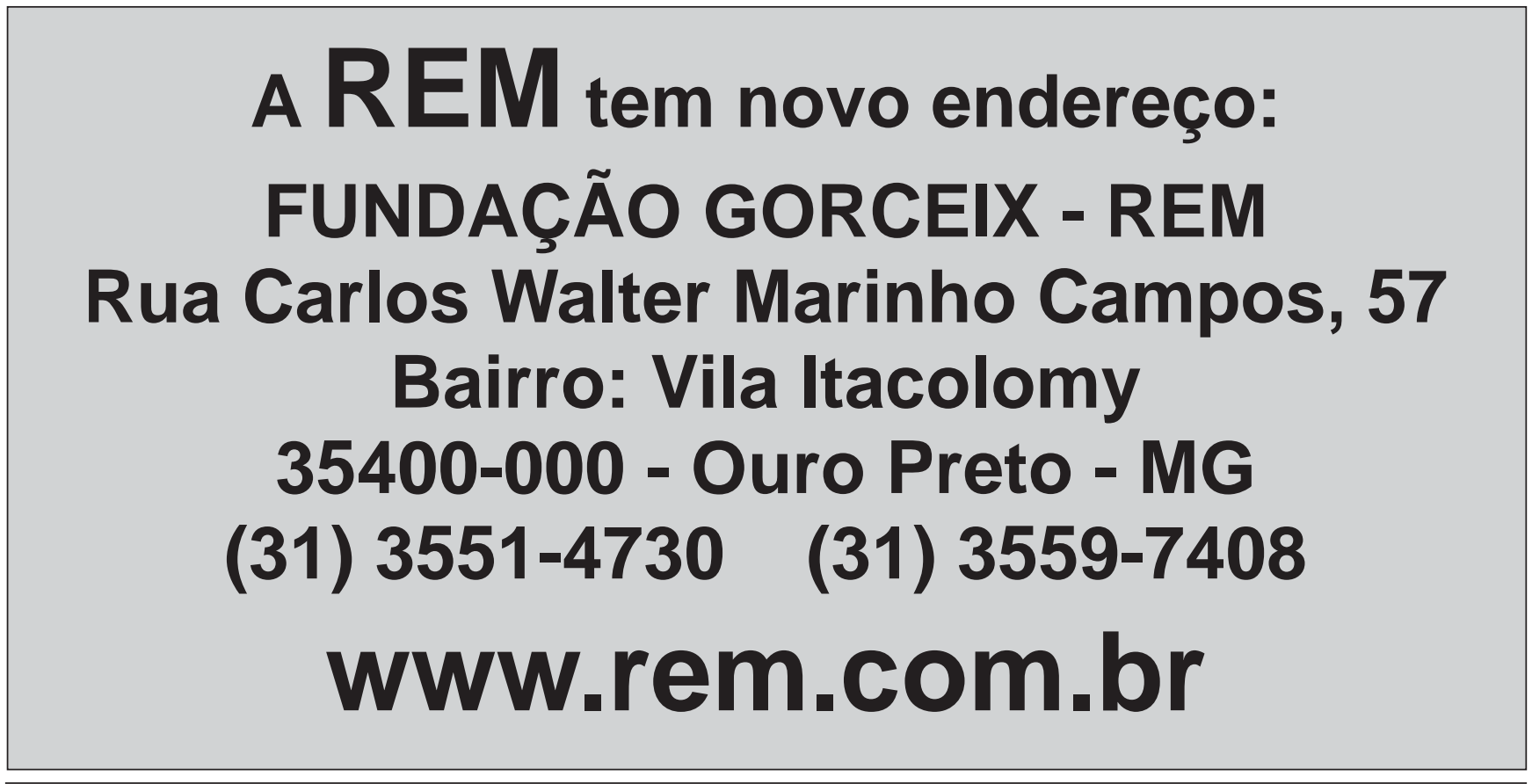

